\title{
2018 年八五五农场肥料利用率试验研究
}

隋文成 纪伟波

黑龙江省密山市八五五农场

DOI:10.32629/as.v2i3.1594

[摘 要] 为了掌握八五五农场玉米氮肥、磷肥、钾肥的利用率, 验证配方制订的参数, 优化测土配方施肥效果, 2018 年开展了玉 米肥料利用率试验。

[关键词] 玉米; 测土配方施肥; 利用率

为了掌握八五五农场玉米氮肥、磷肥、钾肥的利用率， 验证配方制订的参数, 优化测土配方施肥效果, 2018 年开展 了玉米常规施肥与配方施肥提高肥料利用率对比试验。试验 情况如下:

\section{1 材料与方法}

1.1 试验材料

供试作物: 玉米。

供试品种: 德美亚 3 号。

1.2 试验地点

试验地点设在八五五农场科技园区, 东经 $131 \sim$ $35^{\prime} 17.58^{\prime \prime}$, 北纬 $45^{\circ} 44^{\prime} 6.36^{\prime \prime}$, 海拔 143 米。试验田地势平 坦, 肥力中等, 前茬大豆。

\section{3 土壤理化性状}

试验田土类为白浆土, 土壤质地为中壤, pH5. 5, 有机质 $36.0 \mathrm{~g} / \mathrm{kg}$, 碱解氮 $119 \mathrm{mg} / \mathrm{kg}$, 有效磷 $24.2 \mathrm{mg} / \mathrm{kg}$, 速效钾 $146 \mathrm{mg} / \mathrm{kg}$ 。

\section{4 试验肥料}

氮肥为中海石油华鹤煤化有限公司尿素 (46.4\%), 磷肥 为云南云天化国际化工有限公司重过磷酸钙 (44\%), 钾肥为 米高化工有限公司硫酸钾 $(50 \%)$,

\section{2 试验设计}

2.1 试验处理

试验为氮、磷、钾 3 个试验因素, 每个因素设施肥和不 施肥 2 个试验水平, 试验设常规处理和配方处理 2 个大区, 每个大区在分为 5 个小区, 3 次重复。常规处理区分为不施 肥 $\left(\mathrm{N}_{0} \mathrm{P}_{0} \mathrm{~K}_{0}\right)$ 、施磷钾肥不施氮肥 $\left(\mathrm{N}_{0} \mathrm{P}_{2} \mathrm{~K}_{2}\right)$ 、施氮钾肥不施磷肥 $\left(\mathrm{N}_{2} \mathrm{P}_{0} \mathrm{~K}_{2}\right)$ 、施氮磷肥不施钾肥 $\left(\mathrm{N}_{2} \mathrm{P}_{2} \mathrm{~K}_{0}\right)$ 、常规施肥 $\left(\mathrm{N}_{2} \mathrm{P}_{2} \mathrm{~K}_{2}\right) 5$ 个处理。配方处理区分为不施肥 $\left(\mathrm{N}_{0} \mathrm{P}_{0} \mathrm{~K}_{0}\right)$ 、施磷钾肥不施氮 肥 $\left(\mathrm{N}_{0} \mathrm{P}_{2} \mathrm{~K}_{2}\right)$ 、施氮钾肥不施磷肥 $\left(\mathrm{N}_{2} \mathrm{P}_{0} \mathrm{~K}_{2}\right)$ 、施氮磷肥不施钾肥 $\left(\mathrm{N}_{2} \mathrm{P}_{2} \mathrm{~K}_{0}\right)$ 、配方施肥 $\left(\mathrm{N}_{2} \mathrm{P}_{2} \mathrm{~K}_{2}\right) 5$ 个处理。每处理为一个小区, 小 区形状长方形, 每小区面积 $145 \mathrm{~m}^{2}$ 。试验区周围设置保护行。

表 1 试验点常规、配方试验水平养分用量 $(\mathrm{kg} /$ 亩)

\begin{tabular}{|c|c|c|c|c|c|c|}
\hline \multirow{2}{*}{ 处理名称 } & \multicolumn{2}{|c|}{ 尿素 $(46.4 \%)$} & \multicolumn{2}{|c|}{ 重过磷酸铎 (44\%) } & \multicolumn{2}{|c|}{ 硫酸钾 $(50 \%)$} \\
\cline { 2 - 7 } & 纯量 & 商品量 & 纯量 & 商品量 & 纯量 & 商品量 \\
\hline 常规施肥 & 11.7 & 25.4 & 6.8 & 15.45 & 3.5 & 7.0 \\
\hline 配方施肥 & 10.5 & 22.8 & 4.9 & 11.14 & 3.3 & 6.6 \\
\hline
\end{tabular}

\section{2 小区排列}

每个大区内设 5 个处理, 随机排列, 两个大区及 5 个 处理, 每个大区面积均为 $162.5 \mathrm{~m}^{2}$, 每个处理宽 $3.25 \mathrm{~m}$, 长 $10 \mathrm{~m}$ 。

\section{3 主要技术措施}

3.1 土壤样品

每个试验地采集混合土样, 进行常规五项的测定。

3.2 整地

秋收后适墒秋整地。采用大马力机车联合整地或浅翻深 松, 深松深度在 $35 \mathrm{~cm}$ 。

3.3 栽培方式为人工播种与机械播种结合, 栽培密度为 行距 $65 \mathrm{~cm}$, 穴距 $20.0 \mathrm{~cm}$ 。

3.4 施肥时期与方法。

3. 4.1 施肥

分施底肥、种肥和追肥。留 $40 \%$ 尿素作追肥, 剩下的尿 素和重过磷酸钙、硫酸钾总量 $2 / 3$ 作底肥, $1 / 3$ 作种肥。

3. 4.2 播种

播种量: 5 穴/米、每穴 2-3 粒。

播种时间: 4 月 29 日。

注：玉米出苗后及时间苗, 保证每穴一株健壮苗。

3. 4.3 追肥

于玉米 8-10 叶期, 用 40\%尿素追施于根侧 5 8 cm, 深度 8 $10 \mathrm{~cm}$, 追肥后立即中耕培土。

3.5 样品采集

9 月 25 日到试验点测产、调查、采集植株样品, 每小 区内取连续 10 株, 捆好, 2 个标签, 写好试验田名称和处理 名称, 待室内考种使用。取剩余样品进行人工收获, 捆好, 2 个标签, 写明试验点名称和处理名称, 待脱粒测产。

3.6 室内考种将采集来的样品, 进行穗数、毛重、穗长、 穗粗、轴粗、秃尖、行数、穗粒重、株高、水分、穗粒数、 百粒重、株高、株重的测定, 求出产量。用脱粒机按试验点 各处理分别进行脱粒、称重。

3.7 植株检测

将植株样品烘干、粉碎后, 进行秸秆和籽粒全氮、全磷 及全钾养分含量的检测。

\section{4 结果与分析}


4.1 各试验点考种调查结果

表 2 考种调查表

\begin{tabular}{|c|c|c|c|c|c|c|c|c|}
\hline 名称 & \begin{tabular}{|l|} 
株高 \\
$\mathrm{m} /$ 株
\end{tabular} & $\begin{array}{l}\text { 穗长 } \\
\mathrm{cm} / \text { 穗 }\end{array}$ & $\begin{array}{l}\text { 穗粗 } \\
\mathrm{cm} / \text { 穗 }\end{array}$ & \begin{tabular}{|l|} 
轴粗 \\
$\mathrm{cm} /$ 穗
\end{tabular} & $\begin{array}{l}\text { 秃尖 } \\
\mathrm{cm} / \text { 穗 }\end{array}$ & \begin{tabular}{|l|} 
粒数 \\
粒/穗
\end{tabular} & 百粒重 $g$ & $\begin{array}{l}\text { 理论产量 } \\
\mathrm{Kg} / \text { 亩 }\end{array}$ \\
\hline 常规空白 & \begin{tabular}{|l|}
1.7 \\
\end{tabular} & 12.3 & 3.6 & 2.5 & 2.3 & \begin{tabular}{|l|}
256.2 \\
\end{tabular} & 23.8 & 282 \\
\hline 常规无氮 & \begin{tabular}{|l|}
1.9 \\
\end{tabular} & 14.7 & 4.2 & 2.4 & 1.9 & 336.2 & 24.0 & 373 \\
\hline 常规无磷 & 2.1 & 15 & 4.1 & 2.6 & 1.5 & 423.9 & 24.9 & 487 \\
\hline 常规无钾 & 2.0 & 16.1 & 4.3 & 2.5 & 0.6 & 482.4 & 25.6 & 570 \\
\hline 常规施肥 & 2.2 & 17.5 & 4.4 & 2.4 & 0.1 & 525.1 & 28.7 & 696 \\
\hline 配方空白 & 1.8 & 12 & 3.5 & 2.5 & 2.5 & 261.0 & 23.5 & 283 \\
\hline 配方无氮 & 2.1 & 15.5 & 4.1 & 2.5 & 1.7 & 325.4 & 26.0 & 391 \\
\hline 配方无磷 & 2.0 & 16.2 & 4.5 & 2.6 & 1.3 & 465.3 & 24.7 & 531 \\
\hline 配方无钾 & 2.2 & 17.1 & 4.8 & 2.5 & 0.8 & 490.9 & 25.8 & 585 \\
\hline 配方施肥 & 2.2 & 17.5 & 4.7 & 2.2 & 0.2 & 513.9 & 29.6 & 702 \\
\hline
\end{tabular}

通过以上试验点的考种表可知: 不同施肥处理对玉米产 量有不同的影响, 无论是配方施肥还是常规施肥, 增产效果 最明显是氮肥。无钾、无磷、无氮区玉米的综合性状依次变 差, 说明氮磷钾对玉米的是作用为氮〉磷〉钾。常规与配方无 肥区养分供应不足, 秃尖明显, 叶片黄, 穗粒数最少, 百粒重 也最轻。

4.2 试验点不同处理脱粒产量的调查

对试验点各处理采集来的样品进行考种, 秸秆称重折算 秸秆产量, 其余全区脱粒测产, 详见表 3 。

\section{表 3 脱粒产量的调查表 $\mathrm{kg} /$ 亩}

\begin{tabular}{|l|l|l|l|l|l|l|l|l|l|l|}
\hline 名称 & $\begin{array}{l}\text { 常规 } \\
\text { 空白 }\end{array}$ & $\begin{array}{l}\text { 常规 } \\
\text { 无氮 }\end{array}$ & 常规 \\
无磷 & $\begin{array}{l}\text { 常规 } \\
\text { 无钾 }\end{array}$ & $\begin{array}{l}\text { 常规 } \\
\text { 施肥 }\end{array}$ & $\begin{array}{l}\text { 配方 } \\
\text { 空白 }\end{array}$ & $\begin{array}{l}\text { 配方 } \\
\text { 无氮 }\end{array}$ & $\begin{array}{l}\text { 配方 } \\
\text { 无磷 }\end{array}$ & $\begin{array}{l}\text { 配方 } \\
\text { 无钾 }\end{array}$ & $\begin{array}{l}\text { 配方 } \\
\text { 施肥 }\end{array}$ \\
\hline $\begin{array}{l}\text { 籽粒 } \\
\text { 产量 }\end{array}$ & 214.1 & 364.4 & 508.1 & 612.5 & 701.0 & 211.6 & 365.2 & 514.3 & 615.0 & 707.7 \\
\hline $\begin{array}{l}\text { 秸秆 } \\
\text { 产量 }\end{array}$ & 262.3 & 408.2 & 608.9 & 636.1 & 621.3 & 232.4 & 458.5 & 616.3 & 613.3 & 621.4 \\
\hline
\end{tabular}

通过上表可知: 无论是常规氮磷钾施肥还是配方氮磷钾 施肥, 䊏粒产量和秥秆产量基本都高于不施肥和缺失肥料的 处理, 说明在氮磷钾三种肥料的共同作用下有利于玉米产量 的增加。

4.3 试验点不同处理植株检测结果

根据百公斤经济产量养分吸收量与肥料利用率公斤计 算相关参数。
表 4 植株养分含量检测结果汇总表 $\mathrm{g} / \mathrm{kg}$

\begin{tabular}{|c|c|c|c|c|c|c|c|c|c|}
\hline \multirow[t]{2}{*}{ 名称 } & \multirow{2}{*}{$\begin{array}{l}\text { 籽粒 } \\
\text { 全氮 }\end{array}$} & \multirow{2}{*}{$\begin{array}{l}\text { 籽粒 } \\
\text { 全磷 }\end{array}$} & \multirow{2}{*}{$\begin{array}{l}\text { 䊏粒 } \\
\text { 全钾 }\end{array}$} & \multirow{2}{*}{$\begin{array}{l}\text { 秥秆 } \\
\text { 全氮 }\end{array}$} & \multirow{2}{*}{$\begin{array}{l}\text { 秥秆 } \\
\text { 全磷 }\end{array}$} & \multirow{2}{*}{$\begin{array}{l}\text { 秸秆 } \\
\text { 全钾 }\end{array}$} & \multicolumn{3}{|c|}{$\begin{array}{l}\text { 每形成 } 100 \mathrm{~kg} \text { 经㳔 } \\
\text { 产量养分吸收量 }(\mathrm{k}\end{array}$} \\
\hline & & & & & & & $\mathrm{N}$ & P205 & К20 \\
\hline 常规空白 & 9.52 & 3.50 & 2.42 & 5.61 & 2.24 & 7.05 & 9.52 & 3.50 & 2.42 \\
\hline 常规无氮 & 9.30 & 3. 16 & 3. 29 & 5. 45 & 2. 56 & 8.10 & 9. 30 & 3. 16 & 3. 29 \\
\hline 常规无磷 & 10.81 & 3. 36 & 2.67 & 5. 42 & 2.29 & 8.01 & $\begin{array}{c}10.8 \\
1\end{array}$ & 3. 36 & 2.67 \\
\hline 常规无钾 & 10.15 & 2. 94 & 2. 77 & 5. 99 & 2. 24 & 7. 66 & $\begin{array}{c}10.1 \\
5\end{array}$ & 2. 94 & 2. 77 \\
\hline 常规施肥 & 9.65 & 3.02 & 3.19 & 5.11 & 2.13 & 7.72 & 9.65 & 3.02 & 3.19 \\
\hline 配方空白 & 10.23 & 3. 10 & 2. 60 & 6. 22 & 2. 06 & 8.22 & $\begin{array}{c}10.2 \\
3\end{array}$ & 3. 10 & 2. 60 \\
\hline 配方无氮 & 10. 18 & 3. 20 & 2. 48 & 7. 11 & 2. 12 & 8.81 & $\begin{array}{c}10.1 \\
8\end{array}$ & 3. 20 & 2. 48 \\
\hline 配方无磷 & 10.33 & 2. 71 & 2. 27 & 4. 43 & 1.62 & 8. 70 & $\begin{array}{c}10.3 \\
3\end{array}$ & 2.71 & 2. 27 \\
\hline 配方无钾 & 9.60 & 2.79 & 2.61 & 5.65 & 1.78 & 7.50 & 9.60 & 2.79 & 2.61 \\
\hline 配方施肥 & 9.90 & 2.58 & 2.62 & 6.02 & 1.51 & 8.02 & 9.91 & 2.58 & 2.62 \\
\hline
\end{tabular}

4. 4 肥料利用率

\begin{tabular}{|c|c|c|c|c|c|c|}
\hline \multirow{2}{*}{ 位置 } & \multicolumn{3}{|c|}{ 常规施肥利用率 } & \multicolumn{3}{|c|}{ 配方施肥利用率 } \\
\cline { 2 - 7 } & $\mathrm{N}$ & $\mathrm{P}_{2} \mathrm{O}_{5}$ & $\mathrm{~K}_{2} \mathrm{O}$ & $\mathrm{N}$ & $\mathrm{P}_{2} \mathrm{O}_{5}$ & $\mathrm{~K}_{2} \mathrm{O}$ \\
\hline 科技园区 & 36.97 & 11.41 & 15.96 & 35.90 & 17.39 & 23.11 \\
\hline
\end{tabular}

\section{5 结论}

5.1 从试验结果可知, 配方施肥能有效提高经济性状, 从 而提高产量。配方施肥无氮、无磷、无钾处理比常规施肥无 氮、无磷、无钾处理产量要高, 推荐的施肥配方合理, 符合本 场生产实际。

5.2 常规施肥下氮肥、磷肥和钾肥的利用率分别为 $36.97 \% 、 11.41 \%$ 和 $15.96 \%$ 。配方施肥下氮肥、磷肥和钾肥 的利用率分别为 $35.90 \% 、 17.39 \%$ 和 $23.11 \%$ 。八五五农场配 方施肥情况下, 磷、钾的肥料利用率是配方施肥区大于常规 施肥区 $5.98 \%$ 和 $7.15 \%$, 氮的肥料利用率是常规施肥区大于 配方施肥区 $1.07 \%$ 。为进一步修定八五五农场施肥配方的技 术参数, 提升施肥效果起到重要的作用。

[参考文献]

[1]王恒祥.玉米肥料利用率的试验研究[J].农家科技(下 旬刊),2017,(7):84.

[2]罗元琼,刘军霞.马铃薯肥料利用率试验研究[J].农技 服务,2017,34(17):30-31.

[3]李武.永济市小麦肥料利用率的试验研究[J].农业技 术与装备,2017,(11):10-11+14. 